\title{
Hydrogen Production from Ammonia Using Plasma Membrane Reactor
}

\author{
Shinji Kambara" ${ }^{*}$, Yukio Hayakawa ${ }^{2}$, Yu Inoue ${ }^{3}$, Tomonori Miura ${ }^{4}$ \\ ${ }^{1}$ Energy and Renewable Energy Systems Division, Graduate School of Engineering, Gifu University, 1-1 \\ Yanagido, Gifu, Japan \\ e-mail: kambara@gifu-u.ac.jp \\ ${ }^{2}$ Energy and Renewable Energy Systems Division, Graduate School of Engineering, Gifu University, 1-1 \\ Yanagido, Gifu, Japan \\ e-mail: t3815001@edu.gifu-u.ac.jp \\ ${ }^{3}$ Energy and Renewable Energy Systems Division, Graduate School of Engineering, Gifu University, 1-1 \\ Yanagido, Gifu, Japan \\ e-mail: r3023047@edu.gifu-u.ac.jp \\ ${ }^{4}$ Sawafuji Electric Co., Ltd., 3, Nitta-hayakawa, Ota, Gunma, Japan \\ e-mail: to-miura@sawafuji.co.jp
}

Cite as: Kambara, S., Hayakawa, Y., Inoue, Y., Miura, T., Hydrogen Production from Ammonia Using Plasma Membrane Reactor, J. sustain. dev. energy water environ. syst., 4(2), pp 193-202, 2016, DOI: http://dx.doi.org/10.13044/j.sdewes.2016.04.0016

\begin{abstract}
In this study, an efficient method for using pulsed plasma to produce hydrogen from ammonia was developed. An original pulsed plasma reactor with a hydrogen separation membrane was developed for efficient hydrogen production, and its hydrogen production performance was investigated. Hydrogen production in the plasma was affected by the applied voltage and flow rate of ammonia gas. The maximum hydrogen production flow rate of a typical plasma reactor was $8.7 \mathrm{~L} / \mathrm{h}$, whereas that of the plasma membrane reactor was $21.0 \mathrm{~L} / \mathrm{h}$. We found that ammonia recombination reactions in the plasma controlled hydrogen production in the plasma reactor. In the plasma membrane reactor, a significant increase in hydrogen production was obtained because ammonia recombination reactions were inhibited by the permeation of hydrogen radicals generated in the plasma through a palladium alloy membrane. The energy efficiency was $4.42 \mathrm{~mol}-\mathrm{H}_{2} / \mathrm{kWh}$ depending on the discharge power.
\end{abstract}

\section{KEYWORDS}

Ammonia, Hydrogen, Plasma reactor, Membrane reactor, Dielectric barrier discharge.

\section{INTRODUCTION}

Development of high efficiency power generation systems such as an Integrated Coal Gasification Combined Cycle (IGCC) [1] and an Integrated Coal Gasification Fuel Cell (IGFC) [2] have been accelerated in Japan. In these coal gasification processes, ammonia is generated as a by-product, therefore effective utilization of ammonia is highly in need.

Ammonia has numerous favourable characteristics that stem from its molecular structure - the primary one being its high hydrogen storage capacity of $17.6 \mathrm{wt} \%$. Another advantage is that it is carbon-free in its end uses, although $\mathrm{CO}_{2}$ emitted during the production of ammonia depends on the energy source used. Therefore, ammonia is the most promising hydrogen carrier among all hydrogen-containing compounds [3].

A general technique for producing hydrogen from ammonia is catalytic thermal decomposition. Ammonia decomposition catalysts such as $\mathrm{Ru} / \mathrm{Al}_{2} \mathrm{O}_{3}$ have been

\footnotetext{
* Corresponding author
} 
developed to produce hydrogen at high conversion rates and at the lowest possible temperature [4]. However, a critical issue is the long start-up time for hydrogen production because the process requires heating. For on-demand power generation systems, quick start-up devices are desired.

Compared with the aforementioned technologies, non-catalytic hydrogen production using pulsed plasma may provide a solution to the critical start-up issue. In particular, a Dielectric Barrier Discharge (DBD) plasma is appropriate for ammonia decomposition because the electric load to the plasma reactors can be quickly controlled by adjusting the output voltage or duty cycle, which can respond well to variations in gas volume. Furthermore, ammonia is expected to be completely decomposed by sufficient electron energy in the plasma without the need for heating [5].

Hydrogen production using plasma techniques has been progressed in steam reforming of methane [6], and decomposition of hydrocarbon fuels such as alcohols [7] and gasoline [8]. However, so far the studies of ammonia decomposition by plasma for hydrogen production has been superficial. It has been reported that the ammonia conversion to hydrogen by arc plasma decomposition is $18 \%$ at the power consumption of $227 \mathrm{~W}$ [9], which is a low energy efficiency for hydrogen production.

The present study aimed to develop an efficient method for using pulsed plasma to produce hydrogen from ammonia. The effects of applied voltages, ammonia concentrations and ammonia flow rates on hydrogen production were examined using a typical pulsed plasma reactor. As an efficient method for producing hydrogen, an original pulsed plasma reactor with hydrogen separation membrane was developed, and its hydrogen production performance was investigated.

\section{EXPERIMENTAL}

Two different plasma reactors with and without a hydrogen separation membrane were prepared for the hydrogen production experiment. Figure 1 shows a plasma reactor without a hydrogen separation membrane (Plasma Reactor: PR); it was used to examine the fundamental characteristics of hydrogen production from ammonia by pulsed plasma. Figure 2 shows a plasma reactor with hydrogen separation membrane (Plasma Membrane Reactor: PMR); it was used to improve hydrogen production efficiency. In both reactors, the electrodes had a coaxial configuration with quartz glass tubes as the dielectric material.

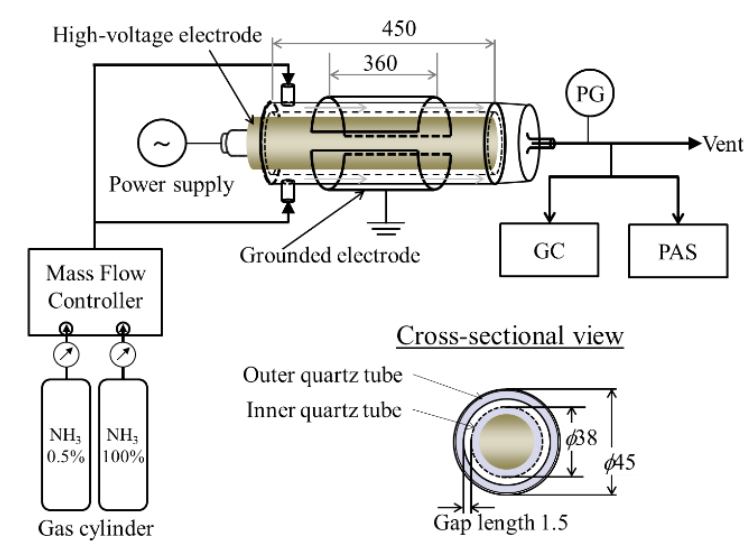

Figure 1. Experimental setup for hydrogen production by plasma reactor

The PR experimental setup is shown in Figure 1. The outer glass tube was $45 \mathrm{~mm}$ in diameter and $2 \mathrm{~mm}$ in thickness, whereas the inner glass tube was $38 \mathrm{~mm}$ in diameter and 
$2 \mathrm{~mm}$ in thickness. The pulsed plasma was generated in a $1.5 \mathrm{~mm}$ gap between the outer and inner glass tubes. The grounded electrode was made of stainless steel (SUS 304). It was $360 \mathrm{~mm}$ in length and $0.2 \mathrm{~mm}$ in thickness and covered the outside surface of the outer glass tube. The high-voltage electrode was made of stainless steel (SUS 304). It was $34 \mathrm{~mm}$ in diameter and $450 \mathrm{~mm}$ in length and was positioned inside the inner quartz tube.

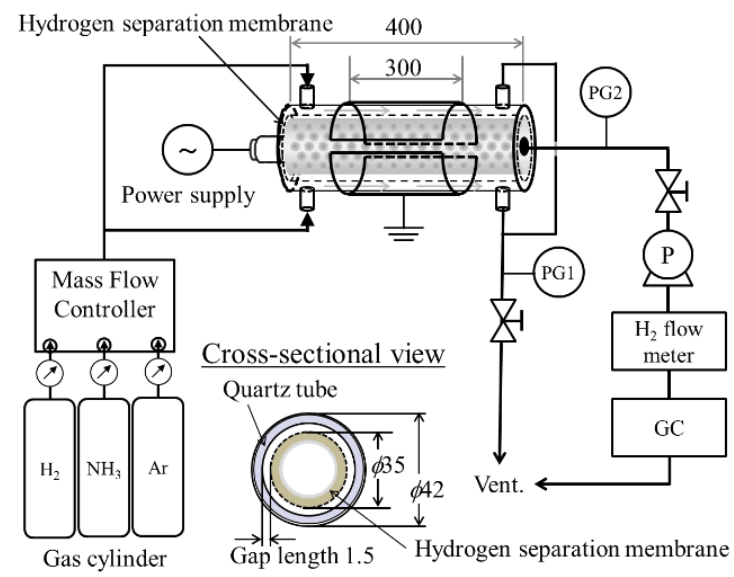

Figure 2. Experimental setup for hydrogen production by PMR

Figure 2 shows the PMR experimental setup. The PMR consisted of a glass tube and a hydrogen separation membrane module made by Nippon Seisen Co., Ltd. [10]. In this module, a palladium alloy membrane of $20 \mu \mathrm{m}$ thickness was carefully welded inside a thin punched metal (SUS 304). The hydrogen separation membrane module served as the high-voltage electrode of the PMR. The PMR length was $400 \mathrm{~mm}$, whereas the grounded electrode length was $300 \mathrm{~mm}$. The gap length was $1.5 \mathrm{~mm}$, same as that in the PR. The gap volumes of the PR and PMR were 67.0 and $51.6 \mathrm{~cm}^{3}$, respectively.

To analyse the concentration of hydrogen generated at the reactor exit, micro Gas Chromatography (GC) system (Agilent 3000A) with a capillary column of molecular sieve $5 \mathrm{~A}$ was prepared. The concentration of unreacted ammonia was continuously measured using photo acoustic spectroscopy (PAS: Gasera F10). In the PMR experiments, the flow rates of the produced hydrogen were directly measured by mass flow meter (Figure 2).

A pulsed high-voltage power source (Sawafuji Co., Ltd.) was used to generate the pulsed DBD plasma. Figure 3 depicts the waveform of the applied voltage observed in the $\mathrm{NH}_{3} / \mathrm{Ar}$ gas mixture. The applied voltage $V_{p p}$ is defined as the peak-to-peak value measured using an oscilloscope (Tektronix, TDS3034B) with a high voltage probe (Tektronix, P6015A) and current probe (Tektronix, P6021). The duration of one cycle of the waveform, $T_{1}$, was approximately $100 \mu$ s during the experiments. The discharge power in the plasma was estimated from the discharge energy per one cycle of the applied voltage multiplied by the repetition rate. The energy was calculated by analysing a Lissajous figure comprising the accumulated charge on a series capacitor and the source voltage [11].

Table 1 lists the experimental conditions in the PR and PMR experiments. In the PR experiments, $0.5 \%$ ammonia gas diluted with argon or $100 \%$ ammonia gas was supplied to the reactor, whereas $100 \%$ ammonia gas was used for hydrogen production in the PMR experiments. The flow rates of ammonia gas were adjusted between 0.2 and $4.0 \mathrm{~L} / \mathrm{min}$ using mass flow controllers. The repetition rate of the power source was fixed at $10 \mathrm{kHz}$. The applied voltages were varied from 3.5 to $22 \mathrm{kV}$. 


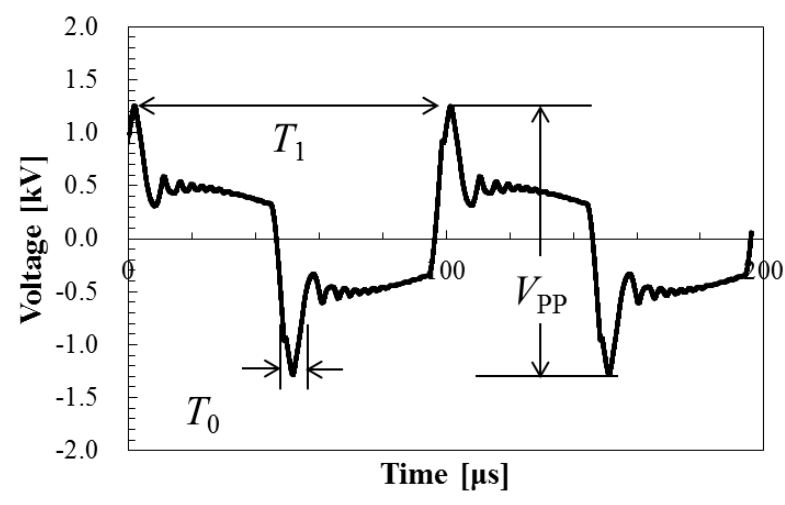

Figure 3. Waveform of applied voltage for $\mathrm{NH}_{3} / \mathrm{Ar}$ gas mixture

Table 1. Experimental conditions

\begin{tabular}{cccc}
\hline $\mathrm{NH}_{3}$ concentration & {$[\%]$} & 0.5 & 100 \\
\hline Flow rate $F_{0}$ & {$[\mathrm{~L} / \mathrm{min}]$} & $0.2-2.0$ & $0.3-4.0$ \\
Repetition rate $R_{R}$ & {$[\mathrm{kHz}]$} & 10 & 10 \\
Applied voltage $V_{p p}$ & {$[\mathrm{kV}]$} & $3.5-15.0$ & $18.0-22.0$ \\
\hline
\end{tabular}

\section{RESULTS AND DISCUSSION}

\section{Fundamental characteristics of hydrogen yield by the PR}

First, the effects of the applied voltage and flow rates on hydrogen yield were examined using the PR. In the DBD pulsed plasma, electrons collide with background Ar gas molecules, wherein subsequent secondary and tertiary electron collisions convert a fraction of $\mathrm{NH}_{3}$ into positive ions, radicals and electrons. $\mathrm{NH}_{2}, \mathrm{NH}, \mathrm{N}$ and $\mathrm{H}$ radicals are also generated by electron impact reactions. After their generation, molecular hydrogen and nitrogen are formed by recombination reactions. The overall reaction of ammonia decomposition by the pulsed DBD plasma is given by eq. (1):

$$
\mathrm{NH}_{3}+\mathrm{e} \rightarrow 0.5 \mathrm{~N}_{2}+1.5 \mathrm{H}_{2}+\mathrm{e}
$$

Figure 4 shows hydrogen yield as a function of $V_{p p}$ for the $0.5 \%$ ammonia gas flow rates, which ranged from 0.2 to $2.0 \mathrm{~L} / \mathrm{min}$. The hydrogen yield was calculated according to the following equation:

$$
\mathrm{H}_{2} \text { yield, } \%=\left[\mathrm{H}_{2}\right] \mathrm{m} /\left[\mathrm{H}_{2}\right] \mathrm{s} \times 100
$$

where $\left[\mathrm{H}_{2}\right]_{\mathrm{m}}$ is the measured $\mathrm{H}_{2}$ concentration by $\mathrm{GC}$ at the $\mathrm{PR}$ exit, and $\left[\mathrm{H}_{2}\right]_{\mathrm{s}}$ is the stoichiometric concentration of $\mathrm{H}_{2}$ according to eq. (1). For example, $\left[\mathrm{H}_{2}\right]_{\mathrm{s}}$ is $0.746 \%$ for the $0.5 \%$ ammonia gas.

Hydrogen yield increased with increasing $V_{p p}$ at all gas flow rates. The concentration of $\mathrm{H}$ radicals in the pulsed DBD plasma is a function of the electron mean energy, which depends on the discharge energy for plasma or the power consumption of the power source at the plug. Table 2 details the variation in the discharge energy and power consumption with change in $V_{p p}$. The discharge energy and power consumption increased proportionally with increasing $V_{p p}$. Therefore, an increase in $V_{p p}$ facilitates hydrogen production in the gas phase reactions. The hydrogen yield achieved was $96.3 \%$ at a flow rate of $0.2 \mathrm{~L} / \mathrm{min}$ and $V_{p p}$ of $15 \mathrm{kV}$. However, it should be noted that a gradual increase in hydrogen yield was observed at a high $V_{p p}$. 
An increase in the flow rates of the $0.5 \%$ ammonia gas decreased the hydrogen yield, as shown in Figure 4. Figure 5 depicts the effect of the flow rates as a relationship between gas residence time at a standard condition and hydrogen yield. At $V_{p p}=15 \mathrm{kV}$, the hydrogen yield proportionally increased with increasing gas residence time, up to $5.0 \mathrm{~s}$. Beyond this time, a gradual increase in hydrogen yield was observed.

Such a gradual increase in hydrogen yield was observed at a high $V_{p p}$ and the long residence time shown in Figures 4 and 5 indicates that ammonia was formed again through a recombination reaction between $\mathrm{H}$ and $\mathrm{NH}_{\mathrm{i}}$ radicals as follows:

$$
\begin{aligned}
& \mathrm{NH}_{2}+\mathrm{H} \rightarrow \mathrm{NH}_{3} \\
& \mathrm{NH}+2 \mathrm{H} \rightarrow \mathrm{NH}_{3}
\end{aligned}
$$

For efficient hydrogen production from ammonia, reverse reactions to ammonia should be inhibited.

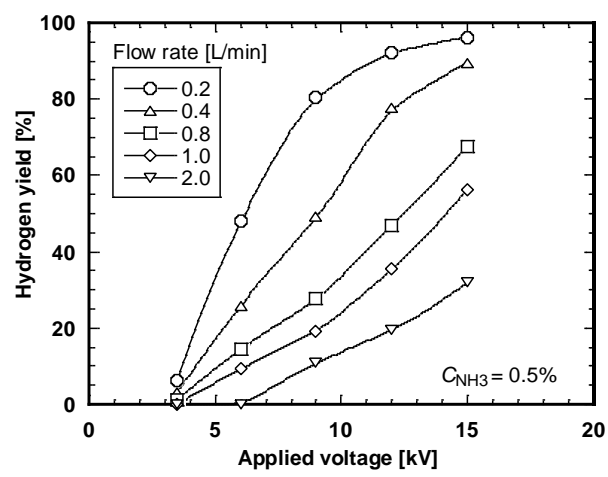

Figure 4. Effect of $V_{p p}$ on hydrogen yield as a parameter of flow rates of $0.5 \%$ ammonia gas

Table 2. Input power and power consumption of PR for $0.5 \%$ ammonia gas supply

\begin{tabular}{ccccccc}
\hline Applied voltage $V_{p p}$ & {$[\mathrm{kV}]$} & 3.5 & 6.0 & 9.0 & 12.0 & 15.0 \\
Discharge power & {$[\mathrm{W}]$} & 5.2 & 7.7 & 13.4 & 28.9 & 55.6 \\
Power consumption $P$ & {$[\mathrm{~W}]$} & 11.4 & 17.0 & 29.5 & 63.6 & 122.4 \\
\hline
\end{tabular}

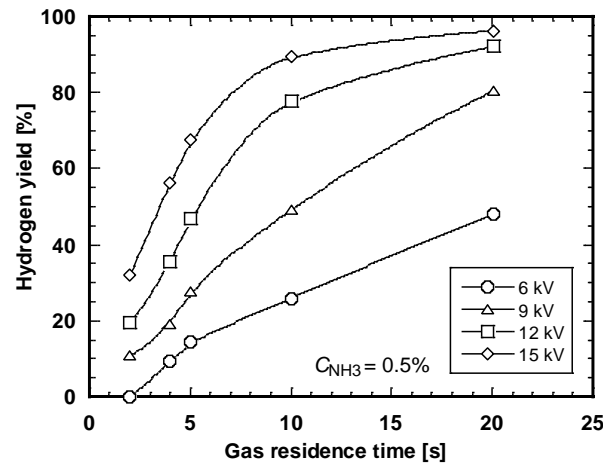

Figure 5. Effect of gas residence time on hydrogen yield as a parameter of $V_{p p}$

\section{Performance of hydrogen production of the PR}

Using $100 \%$ ammonia gas, the maximum hydrogen production performance was obtained by the PR. Furthermore, it can be expected that reverse reactions from hydrogen 
to ammonia formation were controlled by the high ammonia concentration because the partial pressure of the generated hydrogen diminished.

Figure 6 shows hydrogen yield as a function of discharge energy for the 100\% ammonia gas. The discharge power and power consumption corresponding to $V_{p p}$ are listed in Table 3 . Figure 7 depicts variation in the flow rates of hydrogen production with gas residence time. The maximum hydrogen yield was $14.0 \%$ at a flow rate of $0.3 \mathrm{~L} / \mathrm{min}$ and $V_{p p}$ of 22.0 $\mathrm{kV}$ (Figure 6), whereas the maximum flow rate of hydrogen yield calculated by eq. (5) was $8.7 \mathrm{~L} / \mathrm{h}$ at a flow rate of $2.0 \mathrm{~L} / \mathrm{min}$ and $V_{p p}$ of $22.0 \mathrm{kV}$ (Figure 7):

$$
F_{\mathrm{H}_{2}}, \mathrm{~L} / \mathrm{h}=(\text { Hydrogen yield, } \%) \times\left[F_{\mathrm{H}_{2}}\right]_{\mathrm{S}} \times 60
$$

where $F_{\mathrm{H}_{2}}$ is the flow rate of the generated hydrogen and $\left[F_{\mathrm{H}_{2}}\right]_{\mathrm{S}}$ is the $\mathrm{H}_{2}$ flow rate at stoichiometry according to eq. (1). For example, $\left[F_{\mathrm{H}_{2}}\right]_{\mathrm{s}}$ is $3.0 \mathrm{~L} / \mathrm{min}$ for the $100 \%$ ammonia flow rate of $2.0 \mathrm{~L} / \mathrm{min}$.

As shown in Figure 6, we found that the performance of hydrogen production of the PR was insufficient for use as a hydrogen generator, because it would be difficult for the fuel cells to obtain a high hydrogen concentration. This is because the reverse reactions were somewhat encouraged by increasing the gas residence time at $V_{p p}=20.5$ and $22 \mathrm{kV}$, as shown in Figure 7.

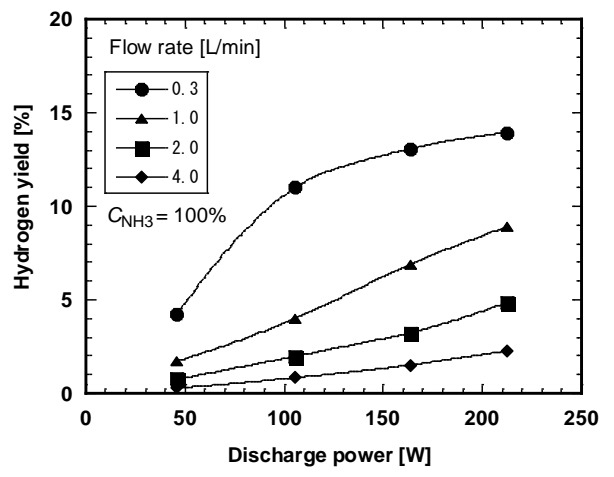

Figure 6. Hydrogen yield as a function of discharge power for $100 \%$ ammonia gas

Table 3. Input power and power consumption for $100 \%$ ammonia gas supply

\begin{tabular}{cccccc}
\hline Applied voltage $V_{p p}$ & {$[\mathrm{kV}]$} & 18.0 & 19.0 & 20.5 & 22.0 \\
Discharge power & {$[\mathrm{W}]$} & 46.1 & 105.3 & 163.7 & 212.3 \\
Power consumption $P$ & {$[\mathrm{~W}]$} & 100 & 200 & 300 & 400 \\
\hline
\end{tabular}

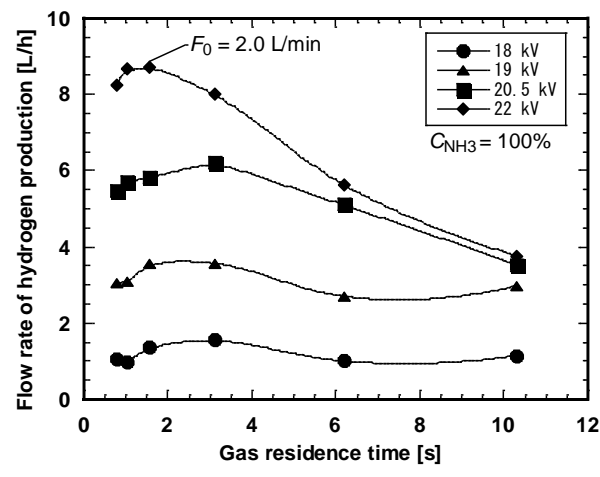

Figure 7. Variation in flow rates of $\mathrm{H}_{2}$ production with gas residence time 


\section{Hydrogen separation performance of the PMR}

The ammonia recombination reactions must be controlled to attain a high efficiency of hydrogen production. In other words, the $\mathrm{H}$ radicals generated in the plasma must be removed from the plasma region. To achieve this, we precisely designed the advanced plasma reactor shown in Figure 2. We expected the $\mathrm{H}$ radicals generated by ammonia decomposition in the plasma to diffuse rapidly through the membrane, thereby inhibiting ammonia recombination.

Prior to the hydrogen production experiments by the PMR, pure hydrogen was supplied to the PMR to examine the hydrogen separation characteristics of the membrane. Figure 8 shows the hydrogen separation characteristics of the PMR as variables of induced pressure (PG2 in Figure 2) and feed pressure (PG1 in Figure 2). The applied voltage and pure $\mathrm{H}_{2}$ flow rate were fixed at $14 \mathrm{kV}$ and $60 \mathrm{~L} / \mathrm{h}$, respectively. The grounded electrode was heated by joule heating from the power source. It's surface temperature was $408 \mathrm{~K}$, which was measured by a radiation thermometer (Hioki 3460-50).

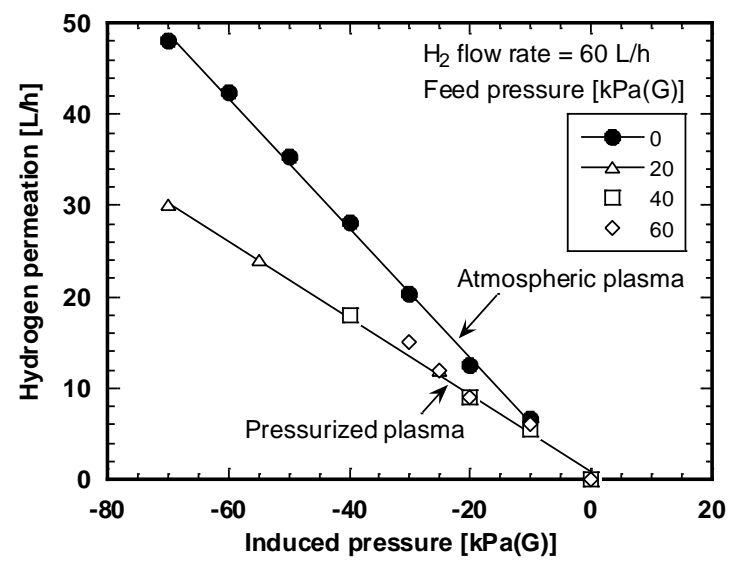

Figure 8. Hydrogen separation characteristics of PMR for pure hydrogen supply

The flow rate of hydrogen permeation increased proportionally with an increase in induced pressure. It is well known that the performance of hydrogen permeation through a palladium membrane is proportional to the differential pressure between PG1 and PG2 [12]. Meanwhile, an increase in feed pressure reduced the flow rate of hydrogen permeation. The concentration of $\mathrm{H}$ radicals in the plasma may decrease under pressurised plasma relative to atmospheric plasma.

The strongest point of the PMR is that hydrogen permeation is unnecessary at high temperatures owing to the generation of $\mathrm{H}$ radicals in low-temperature plasma. In general, palladium alloy membranes are effective at $673 \mathrm{~K}$ [13]. However, attention should be paid to the problem of hydrogen absorption below a critical temperature (571 K) [14].

Hydrogen permeation in the PMR is estimated from a solution diffusion mechanism [15], as follows:

- Molecular ammonia is rapidly decomposed to $\mathrm{N}$ and $\mathrm{H}$ radicals by electron impact in plasma;

- Generated $\mathrm{H}$ radicals are adsorbed onto the surface of the hydrogen separation membrane; consequently, ammonia recombination in the gas phase is inhibited;

- H radicals diffuse through the membrane;

- Molecular hydrogen is subsequently formed by recombination outside the membrane.

The estimated mechanism is illustrated in Figure 9. 


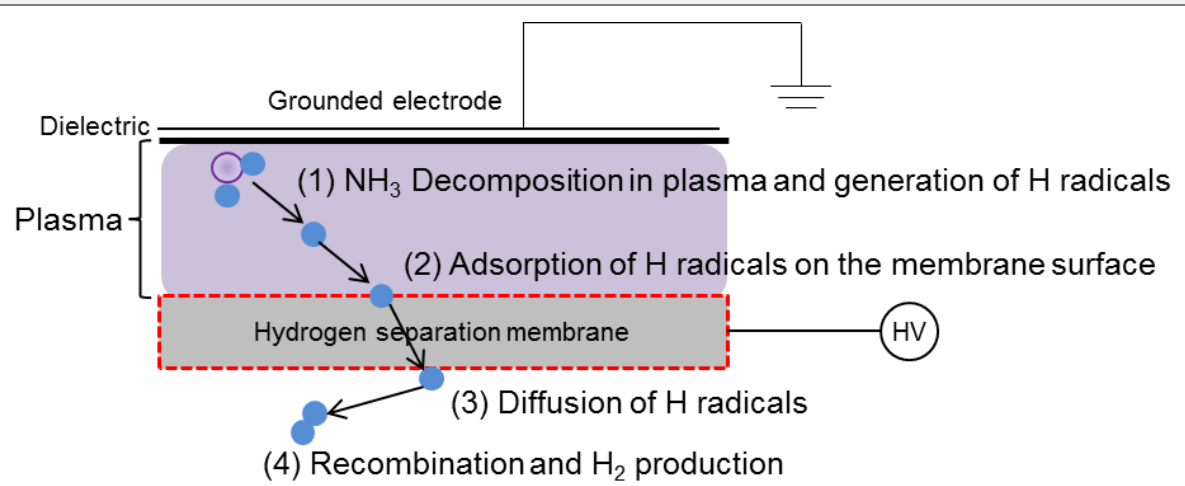

Figure 9. Estimated mechanism of hydrogen separation in PMR

\section{Hydrogen production performance of the PMR}

Hydrogen production experiments were conducted in the PMR using the $100 \%$ ammonia gas at various flow rates (Table 1). Feed pressure and induced pressure were 0 $\mathrm{kPa}(\mathrm{G})$ and $70 \mathrm{kPa}(\mathrm{G})$, respectively; maximum hydrogen permeation performance of the membrane was $48 \mathrm{~L} / \mathrm{h}$, as shown in Figure 8 . Therefore, maximum hydrogen production of $48 \mathrm{~L} / \mathrm{h}$ is expected in the PMR experiments, if reverse reactions from hydrogen to ammonia in eqs. (3) and (4) can inhibit by effect of the membrane. The surface temperature of the grounded electrode was $573 \mathrm{~K}$ at $V_{p p}$ of $22 \mathrm{kV}$.

Figure 10 shows variation in the flow rates of hydrogen production with an increase in the flow rate of ammonia gas for both the PMR and PR. The hydrogen production by the PR was constant above the $\mathrm{NH}_{3}$ flow rate of $60 \mathrm{~L} / \mathrm{h}$. This result indicated that ammonia decomposition in eq. (1) is reached equilibrium in plasma. On the other hand, the hydrogen production of the PMR represented a significant increase compared with that of the PR. This result indicates that ammonia recombination in plasma is inhibited by using a hydrogen separation membrane, and equilibrium is moved to hydrogen production side in eq. (1).

The maximum hydrogen production flow rate in the PMR was $21.0 \mathrm{~L} / \mathrm{h}$ at the $\mathrm{NH}_{3}$ flow rate of $30 \mathrm{~L} / \mathrm{h}$, which is equivalent to complete decomposition of the $\mathrm{NH}_{3}$ flow rate of $14 \mathrm{~L} / \mathrm{h}$. Therefore, it was found that the ammonia decomposition in the plasma was a rate-controlling step in eq. (1). The energy efficiency was $4.42 \mathrm{~mol}-\mathrm{H}_{2} / \mathrm{kWh}$ depending on the discharge power.

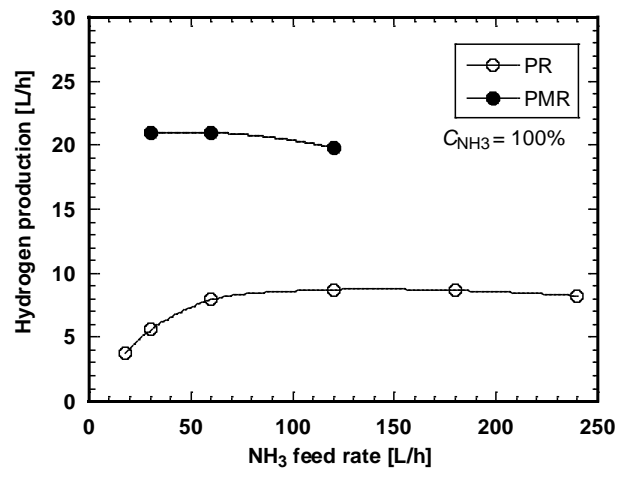

Figure 10. Hydrogen production performance of the PMR and PR

\section{CONCLUSION}

Ammonia is a hydrogen storage material that may solve many problems related to hydrogen transportation and storage in a hydrogen economy. Therefore, devices that 
produce hydrogen from ammonia will become increasingly important. In this study, hydrogen production experiments were conducted to develop an efficient method for using pulsed plasma to produce hydrogen from ammonia.

First, the fundamental characteristics of hydrogen yield were investigated using a typical PR. The hydrogen yield increased with an increase in the applied voltage and with a decrease in the flow rate of ammonia gas.

Second, the hydrogen production performance of the PR was examined using $100 \%$ ammonia gas. However, the performance was inadequate for use as a hydrogen generator. This is because the hydrogen production flow rate was only $8.7 \mathrm{~L} / \mathrm{h}$ because of ammonia recombination reactions in the plasma.

To inhibit reverse reactions from hydrogen to ammonia in the plasma, PMR was developed. The PMR contained a hydrogen separation membrane made from palladium alloy. The maximum hydrogen permeation for the PMR was $48 \mathrm{~L} / \mathrm{h}$, which was affected by the differential pressure between the feed and induced pressures.

Finally, the hydrogen production performance of the PMR was investigated using $100 \%$ ammonia gas. The maximum hydrogen production flow rate of the PMR was $21.0 \mathrm{~L} / \mathrm{h}$, which represents a significant increase compared with that of the PR. The energy efficiency was $4.42 \mathrm{~mol}-\mathrm{H}_{2} / \mathrm{kWh}$ depending on the discharge power. Since the rate-controlling step is the ammonia decomposition in the plasma, an improvement in hydrogen production is expected by investigating the optimum conditions for the plasma decomposition of ammonia.

\section{ACKNOWLEDGEMENT}

The authors would like to acknowledge Nippon Seisen Co., Ltd. for providing the hydrogen separation membrane for this study.

\section{REFERENCES}

1. Shinada, O., Yamada, A. and Koyama, Y., The Development of Advanced Energy Technologies in Japan IGCC: A Key Technology for the 21st Century, Energy Conversion and Management, Vol. 43, pp 1221-1233, 2002, http://dx.doi.org/10.1016/S0196-8904(02)00009-2

2. Lanzini, A., Kreutz, T. G., Martelli, E. and Santarelli, M., Energy and Economic Performance of Novel Integrated Gasifier Fuel Cell (IGFC) Cycles with Carbon Capture, International Journal of Greenhouse Gas Control, Vol. 26, pp 169-184, 2014, http://dx.doi.org/10.1016/j.ijggc.2014.04.028

3. Lan, R, Irvine, J. T. S. and Tao, S., Ammonia and Related Chemicals as Potential Indirect Hydrogen Storage Materials, Int. J. Hydrogen Energy, Vol. 37, No. 2, pp 1482-1494, 2012, http://dx.doi.org/10.1016/j.ijhydene.2011.10.004

4. Di Carlo, A., Vecchione, L. and Del Prete, Z., Ammonia Decomposition over Commercial $\mathrm{Ru} / \mathrm{Al}_{2} \mathrm{O}_{3}$ Catalyst: An Experimental Evaluation at Different Operative Pressures and Temperatures, Int. J. Hydrogen Energy, Vol. 39, No. 2, pp 808-814, 2014, http://dx.doi.org/10.1016/j.ijhydene.2013.10.110

5. Kambara, S., Hayakawa, Y., Masui, M., Miura, T., Kumabe, K. and Moritomi, H., Relation Between Chemical Composition of Dissociated Ammonia by Atmospheric Plasma And DeNOx Characteristics, Nihon Kikai Gakkai Ronbunsyu (B) (in Japanese), Vol. 78, No.789, pp 1038-1042, 2012.

6. Nozaki, T. and Okazaki, K., Non-thermal Plasma Catalysis of Methane: Principles, Energy Efficiency and Applications, Catalysis Today, Vol. 211, pp 29-38, 2013, http://dx.doi.org/10.1016/j.cattod.2013.04.002

7. Sarmiento, B., Brey, J. J., Viera, I., González-Elipe, A. R., Cotrino, J. and Rico, V. J., Hydrogen Production by Reforming of Hydrocarbons and Alcohols in a Dielectric 
Barrier Discharge, J. Power Sources, Vol. 169, pp 140-143, 2007, http://dx.doi.org/10.1016/j.jpowsour.2007.01.059

8. Malik, M. A., Hughes, D., Malik, A., Xiao, S. and Schoenbach, K. H., Study of the Production of Hydrogen and Light Hydrocarbons by Spark Discharges in Diesel, Kerosene, Gasoline, and Methane, Plasma Chemistry and Plasma Processing, Vol. 33, pp 271-279, 2013, http://dx.doi.org/10.1007/s11090-012-9429-1

9. Lu, S., Chen, L., Du, C., Sun X., Li, X. and Yan, J., Experimental Study of Hydrogen Production from Reforming of Methane and Ammonia Assisted by Laval Nozzle Arc Discharge, Int. J. Hydrogen Energy, Vol. 39, pp 19990-19999, 2014, http://dx.doi.org/10.1016/j.ijhydene.2014.10.011

10.http://www.n-seisen.co.jp/en/development/development001.html, [Accessed: 28August-2015]

11.Nagao, I., Nishida, M., Yukimura, K., Kambara, S. and Maruyama, T., NOx Removal Using Nitrogen Gas Activated by Dielectric Barrier Discharge at Atmospheric Pressure, Vacuum, Vol. 65, No. 3-4, pp 481-487, 2002, http://dx.doi.org/10.1016/S0042207X(01)00460-2

12.Sieverts, A. and Krumbhaar, W., Solubility of Gases in Metals and Alloys, Berichte der Deutschen Chemischen Gesellschaft, Vol. 43, pp 893-900, 1910.

13. Yun, S. and Oyama, S. T., Correlations in Palladium Membranes for Hydrogen Separation: A Review, J. Membrane Sci., Vol. 375, No. 1-2, pp 28-45, 2013, http://dx.doi.org/10.1016/j.memsci.2011.03.057

14.Lewis, F. A., The Palladium Hydrogen System, Academic Press, New York, 1967.

15. Yoshida, H., Okuno, K., Naruse, Y. and Kashiwai, T., Metallurgical Considerations on Pd, Pd-alloy and their Metal-Hydrogen Systems, Fusion Science and Technology, Vol. 8, No. 2P2, pp 2388-2394, 1985. 